\title{
¿Cooptación, cooperación o competencia? Microfinanzas y nuevas izquierdas en Bolivia, Ecuador y Nicaragua
}

\author{
Florent Bédécarrats ", Johan Bastiaensen "** y François Doligez ${ }^{* *}$
}

Recibido: enero de 2013 / Aceptado: enero de 2013

La última década ha estado marcada por el resurgimiento de movimientos políticos izquierdistas en Latinoamérica. Sin embargo, la magnitud del alzamiento de estas "nuevas izquierdas" oculta a menudo la relación ambivalente entre estos movimientos y la sociedad, así como su lucha por encontrar alternativas al modelo de desarrollo prevaleciente. A lo largo del continente, el sector de las microfinanzas ha llenado el vacío dejado por los fallos de los bancos públicos, desarrollándose bajo una forma crecientemente comercial. Análisis de Nicaragua, Ecuador y Bolivia revelan que los nuevos gobiernos comparten su desconfianza hacia las IMF (instituciones de microfinanzas). Sin embargo, en la ausencia de alternativas viables para la provisión de servicios financieros, los gobiernos y las microfinanzas se ven obligados a coexistir. El medio en el cual lo hacen varía grandemente, dependiendo de políticas locales y factores institucionales. No obstante, algunas tendencias comunes pueden ser discernidas.

Palabras clave: microfinanzas / desarrollo / izquierda / movimientos sociales / economía política

* Red de Microfinanzas CERISE y doctorando en Ciencias Politicas en la Universidad de París I PanthéonSorbonne. Correo electrónico: f.bedecarrats@cerise-microfinance.org.

**Instituto de Desarrollo de Politicas y Administración (IOB), de la Universidad de Amberes, Bélgica. Correo electrónico: johan.bastiaensen@ua.ac.be.

*** ONG investigativa IRAM y Universidad de Rennes-1. Correo electrónico: f.doligez@iram-fr.org. 


\section{Introducción ${ }^{1}$}

El papel de las microfinanzas en el proceso de desarrollo es sujeto de debate. Luego de recibir reconocimiento mundial con el Año Internacional del Microcrédito de la ONU en 2005 y el Premio Nobel de la Paz a Muhammad Yunus en 2006, las instituciones de microfinanzas (IMF) se encuentran actualmente enfrentadas con las nuevas izquierdas Latinoamericanas, justo donde su crecimiento ha sido más impresionante. Dichos gobiernos izquierdistas han adoptado diferentes posturas ante los actores microfinancieros y el paradigma que ha prevalecido en las últimas dos décadas.

El fenómeno requiere un análisis innovador desde una perspectiva de economía política para comprender esta redefinición disputada del papel de las microfinanzas en los países en donde las fuerzas políticas están recurriendo a un enfoque socialista. Aunque las microfinanzas están siendo cuestionadas en todas partes, en Brasil parece perfilarse un clima de aceptación y complementariedad (Abramovay, Magalhães \& Schröder, 2008), a diferencia de la atmósfera de confrontación observada en Nicaragua (Padilla, 2008). La situación es mucho más ambigua en Bolivia (Bédécarrats \& Marconi, 2009; Mosley, 2009), Ecuador (Rhyne, 2010), y El Salvador.

¿Estamos viendo en Latinoamérica la reintroducción del Estado en un sector que ha madurado bajo un modelo comercial privado? Luego de la "década perdida del desarrollo", ¿nos estamos moviendo hacia una nueva relación entra la élite política y los ciudadanos, una que ofrezca mayor protección a los sectores vulnerables a cambio de su creciente dependencia hacia sus líderes? ¿Deberíamos calificar como populistas los intentos de estos gobiernos que, bajo pretexto de promover un acceso financiero ampliado y tasas de interés más bajas, buscan tomar el control de las IMF?

El discurso prevaleciente raramente va más allá de ortodoxias antagónicas que reivindican la superioridad del Estado o bien la del mercado. Por tanto, es hasta hace poco que algunos actores microfinancieros han comenzado a reconsiderar posibles vínculos con los programas públicos, especialmente en la agricultura y los sectores rurales ${ }^{2}$. En este artículo, comparamos la relación entre el sector de las microfinanzas y los gobiernos de izquierda en tres países latinoamericanos. Después de examinar las tendencias históricas que determinaron estos recientes cambios políticos, resumimos las confrontaciones entre las políticas públicas y las microfinanzas en Bolivia, Nicaragua y Ecuador. Luego proponemos un marco analítico para categorizar las dinámicas que se desarrollan en cada uno de estos países y las estrategias que los actores microfinancieros están utilizando para reposicionarse en este nuevo ambiente.

\footnotetext{
Este artículo se publicó originalmente en Critique Internationale, 2011, (52), 129-153, y fue aprobado para publicación en Third World Quaterly, 2012, 33(1), 12. La traducción del inglés al español fue realizada por Xochitl Membreño y Florent Bédécarrats. El presente análisis da inicio a una agenda de investigación-acción que involucra investigadores, actores micorfinancieros y autoridades públicas. Este trabajo es apoyado por CERISE, IOB, FOROLAC, VLIR, FNRS y eMFP.

Ver, en particular, el seminario internacional organizado por la red latinoamericana de microfinanzas rurales: Políticas públicas y marcos regulatorios para las microfinanzas, forolac-redcamif, llevado a cabo en Managua el 17 y 18 de marzo de 2009 .
} 


\section{El acalorado debate sobre las finanzas del desarrollo}

\subsection{La izquierda latinoamericana: diversas realidades políticas}

Luego de varias décadas de dictaduras represivas, y luego de gobiernos neoliberales cada vez más confrontados, coaliciones izquierdistas volvieron al poder en Venezuela (1999), Brasil (2002), Argentina (2003), Uruguay (2005), Honduras, Chile, Bolivia (2006) Ecuador, Nicaragua (2007), Paraguay (2008), El Salvador (2009) y Perú (2011). El espectacular ascenso de estas nuevas izquierdas bajo la forma de movimientos sociales, partidos políticos y gobiernos no puede ser ignorado por las instituciones financieras y de fomento al desarrollo (Calderón, 2008). De hecho, a pesar de su heterogeneidad, todos estos nuevos actores izquierdistas afirman representar una ruptura ideológica y simbólica del neoliberalismo. Retan deliberadamente los supuestos de ineficiencia estatal, el predominio de la iniciativa privada, y el mercado como modo más efectivo para organizar la sociedad y la economía (Arditi, 2008).

Algunos investigadores analizan esta dinámica política a través de una dicotomía que opone a la izquierda populista, autoritaria y centrada en el Estado a la izquierda social demócrata, más moderada y reformista (Castañeda, 2006). Aunque esta tipología es útil para distinguir los extremos del espectro político de izquierda, induce a una perspectiva simplista que impide entender las fuerzas en juego entre las bases y los mandatarios de organizaciones partidistas, y el proceso que lleva hacia la formulación de políticas (Cameron, 2009). Para entender las múltiples dimensiones en que se llevan a cabo estas interacciones, es importante tomar en cuenta los discursos de las nuevas izquierdas, así como sus intereses e instituciones (Hall \& Taylor, 1996).

Los gobiernos izquierdistas en Latinoamérica afirman encarnar una ruptura con las políticas anteriores y para concretarlo, muchos han emprendido reformas constitucionales profundas. Sin embargo, su capacidad de traducir tales cambios en un modelo de desarrollo alternativo es algo cuestionable. Hasta el momento los gobiernos han promovido una distribución de ingresos más igualitaria, pero han priorizado el mantenimiento de los equilibrios macroeconómicos. En muchos casos, los cambios se han materializado a través de programas ampliados de asistencia social para beneficiar a los más pobres. Aunque estos mecanismos de redistribución crean enormes oportunidades en términos de salud y educación, están basados en modelos de producción existentes - particularmente ingresos fiscales del sector primario - y no están equilibrados con reformas económicas más estructurales (Moreno-Brid \& Paunovic, 2008). Los cambios políticos recientes han hecho poco más que reforzar el trickle down ortodoxo, sin cuestionar el nuevo 'consenso post Washington' (BeasleyMurray, Cameron \& Hersheberg, 2009).

Debemos tener cuidado de no idealizar las relaciones entre los gobiernos, partidos y movimientos sociales. Hay mucho que aprender de las transformaciones y rupturas de alianzas entre las bases de estas organizaciones y los 'representantes profesionales' que surgen con ellas (Beasley-Murray et al., 2009, p. 328). El ascenso de las izquierdas al poder en varios países coincide con la polarización de políticas y el agudizamiento de tensiones entre los que se encuentran en el poder y la oposición. 
Estas crispaciones tienden a empujar a los nuevos gobiernos a movilizar todos los recursos disponibles para consolidar su ascenso popular, incentivando las estrategias clientelistas y la toma de control por el poder ejecutivo de autoridades judiciales.

\section{2 ¿Campeones de la lucha contra la pobreza o usureros?}

La historia económica de Latinoamérica está particularmente marcada por el derrumbe de bancos estatales y de programas de crédito gubernamentales. Las principales herramientas de las finanzas del desarrollo en los años 60 y 70, bancos y programas regidos por el Estado, fueron notables por ser altamente disfuncionales: procedimientos burocráticos e ineficientes, falta de control interno, personal poco calificado y en ocasiones corrupto, además de prioridades definidas en base a tácticas clientelistas (Trivelli \& Venero, 2007). Estos fallos, absorbidos por las finanzas públicas, tuvieron un papel decisivo en las 'crisis de deuda' de muchos países en desarrollo en los años 80 y 90 (Long, 1989). La idea de que tales defectos son intrínsecos a los mecanismos de finanzas públicas se arraigó en las mentes de investigadores, políticos y profesionales del desarrollo (Adams, Graham \& Von Pischke, 1984). La erradicación de los bancos de desarrollo se convirtió en una prioridad de las políticas de ajuste estructural, impuesta por las organizaciones financieras internacionales que se habían vuelto los principales prestamistas de los Estados en bancarrota.

Luego de estas reformas, sectores económicos enteros fueron dejados sin acceso al crédito o al ahorro, aunque estos servicios fueran esenciales para su funcionamiento y crecimiento. Organizaciones comunitarias y ONG (organizaciones no gubernamentales) intentaron remediar esta exclusión financiera por medio de iniciativas a menudo promovidas por antiguos administradores de programas de crédito público, de cooperativas que colapsaron, o por organizaciones religiosas internacionales. A pesar de su diversidad, estas organizaciones convergieron en su oposición a la intervención del Estado en las finanzas del desarrollo (Weber, 2002) y ayudaron a crear las bases de un sector privado de microfinanzas alineado con las políticas fiscales y monetarias de sus gobiernos. Por lo tanto, las IMF se desarrollaron como una forma alternativa de financiamiento, apropiada para el sector informal en rápido crecimiento, y se convirtieron en la solución privilegiada para la pobreza y el subempleo, siendo ideológicamente compatibles con el neoliberalismo (Morduch, 1999).

Con el fin de reducir la dependencia a los subsidios y atraer inversionistas privados, los donantes internacionales que apoyaron el sector pusieron énfasis en su sostenibilidad financiera, presionando a las IMF para que cubrieran sus costos, comercializaran operaciones y generaran excedentes, integróandose así al sistema financiero global (Helms, 2006). Como resultado, un número creciente de ONG de microfinanzas se han convertido en entidades comerciales y las cooperativas de crédito y ahorro han sido marginadas. A pesar de que las microfinanzas usualmente movilizan volúmenes poco significativos en términos macroeconómicos, afectan a una enorme cantidad de personas. El Cuadro 1 contiene indicadores clave para Bolivia, Nicaragua y Ecuador. 
Cuadro 1. Datos clave sobre microfinanzas en Bolivia, Nicaragua y Ecuador

\begin{tabular}{|c|c|c|c|}
\hline & Bolivia & Nicaragua & Ecuador \\
\hline \multicolumn{4}{|l|}{ Inclusión financiera (diciembre 2009) } \\
\hline Número total de prestamistas activos (i) & 1.122 .507 & 686.701 & 1.968 .856 \\
\hline $\begin{array}{l}\text { Prestamistas activos como \% de la población } \\
\text { total }\end{array}$ & $19 \%$ & $20 \%$ & $23 \%$ \\
\hline Prestamistas de microfinanzas activos & 865.464 & 391.375 & 656.986 \\
\hline $\begin{array}{l}\text { Prestamistas de microfinanzas activos como } \\
\% \text { de población total }\end{array}$ & $15 \%$ & $11 \%$ & $8 \%$ \\
\hline \multicolumn{4}{|c|}{ Dimensión y evolución del sector (diciembre 2009) } \\
\hline $\begin{array}{l}\text { Cantidad de crédito fuera de las } \\
\text { microfinanzas (millones de USD) (ii) }\end{array}$ & 4.038 & 1.278 & 10.701 \\
\hline $\begin{array}{l}\text { Cantidad de crédito microfinanciero } \\
\text { (millones de USD) }\end{array}$ & 1.854 & 472 & 1.281 \\
\hline $\begin{array}{l}\text { Participación de las microfinanzas en el } \\
\text { sector financiero nacional }\end{array}$ & $31.5 \%$ & $27.0 \%$ & $10.7 \%$ \\
\hline $\begin{array}{l}\text { Tres principales instituciones } \\
\text { microfinancieras del país }\end{array}$ & $\begin{array}{l}\text { ProCredit, } \\
\text { BancoSol, } \\
\text { FIE }\end{array}$ & $\begin{array}{l}\text { Banex, } \\
\text { ProCredit, } \\
\text { FDL }\end{array}$ & $\begin{array}{l}\text { CrediFé, } \\
\text { Banco } \\
\text { Solidario, } \\
\text { ProCredit }\end{array}$ \\
\hline $\begin{array}{l}\text { Número de prestamistas de las tres } \\
\text { principales IMF }\end{array}$ & 356.279 & 148.219 & 263.132 \\
\hline $\begin{array}{l}\text { Participación de las tres principales IMF en } \\
\text { el sector microfinanciero (\#prestamistas) }\end{array}$ & $41 \%$ & $38 \%$ & $40 \%$ \\
\hline $\begin{array}{l}\text { Portafolio de las tres principales IMF } \\
\text { (millones de USD) }\end{array}$ & 1.038 & 299 & 693 \\
\hline $\begin{array}{l}\text { Participación de las tres principales IMF } \\
\text { en el sector microfinanciero (\#volumen de } \\
\text { préstamos) }\end{array}$ & $56 \%$ & $63 \%$ & $54 \%$ \\
\hline $\begin{array}{l}\text { Crecimiento anual del portafolio del sector } \\
\text { microfinanciero }(2006 \text { - 2009) }\end{array}$ & $28 \%$ & $7 \%$ & $15 \%$ \\
\hline $\begin{array}{l}\text { Crecimiento anual del portafolio de las tres } \\
\text { principales IMF }(2006 \text { - 2009) }\end{array}$ & $32 \%$ & $10 \%$ & $12 \%$ \\
\hline \multicolumn{4}{|l|}{ Tipos de interés y tasas de rendimiento (2008) } \\
\hline $\begin{array}{l}\text { Rendimiento promedio del portafolio del } \\
\text { sector microfinanciero }\end{array}$ & $23.22 \%$ & $31.76 \%$ & $22.47 \%$ \\
\hline $\begin{array}{l}\text { Rendimiento promedio de las tres } \\
\text { principales IMF }\end{array}$ & $19.64 \%$ & $26.55 \%$ & $17.68 \%$ \\
\hline $\begin{array}{l}\text { Rendimiento promedio en equidad del } \\
\text { sector microfinanciero }\end{array}$ & $9.06 \%$ & $6.05 \%$ & $5.65 \%$ \\
\hline $\begin{array}{l}\text { Rendimiento promedio en equidad de las } \\
\text { tres principales IMF }\end{array}$ & $12.99 \%$ & $15.36 \%$ & $19.04 \%$ \\
\hline
\end{tabular}

Fuentes: Datos obtenidos del "Microfinance Information eXchange" (www.mix.org).

(i): ASOFIN (www.asofin-bo.org)

(ii): Instituciones Nacionales Supervisoras de Bancos 
Como estas cifras demuestran, las IMF ya juegan un importante papel en las economías de los países en cuestión y están creciendo rápidamente. Esta expansión no ha venido sin críticas. Debido a la estructura de costos de una actividad al por menor (Rosenberg González \& Narain, 2009), ser una IMF económicamente viable implica cobrar tasas de interés significativamente más altas que las de los bancos tradicionales, como evidencian los rendimientos promedios de portafolio listados arriba $^{3}$. Esta paradoja provoca debates acalorados sobre cuán justos son estos intereses y la capacidad de los pobres de cubrir tales costos, en especial cuando éstos conllevan a ganancias significativas para las IMF (Guérin, Lapenu \& Doligez, 2009). Los partidarios de las microfinanzas señalan los precios prohibitivos de las otras opciones disponibles para los pobres, tales como prestamistas. Argumentando que la restricción principal es la oferta, advierten contra establecer techos sobre las tasas y recomiendan dejar que la competencia y las economías de escala induzcan rebajas. Sin embargo, esto último sólo parece ocurrir parcialmente, pues a pesar de que hayan bajado los tipos de interés en Ecuador, Bolivia y Nicaragua, la eficiencia creciente de las instituciones más grandes alimenta sobre todo sus altos niveles de rentabilidad (véase la parte inferior de la tabla).

Mientras muchos segmentos poblacionales, especialmente en zonas rurales, aún no tienen acceso a las microfinanzas, la excesiva concentración de las instituciones en zonas urbanas ha dado lugar a crisis de sobreendeudamiento regionales y nacionales, algunas veces exacerbadas por el desarrollo del crédito de consumo (Marconi \& Mosley, 2006). En ciertos países, la saturación del mercado ha resultado en prácticas crediticias flojas e incluso imprudentes, deteriorando dramáticamente la calidad del portafolio.

\section{Trayectorias nacionales}

\subsection{El futuro incierto de las microfinanzas en Bolivia}

Bolivia, pionera del microcrédito, se ha convertido en un ejemplo emblemático para las microfinanzas comerciales. Los portafolios de IMF representan el 31.5 por ciento del sistema financiero del país en volumen y el sector sirve a la mayoría (el 70 por ciento) de los clientes (Bédécarrats \& Marconi, 2009, p. 76). Después de una intensa fase de crecimiento en los años 90, durante los cuales llegaron a servir casi a un millón de clientes (sobre todo urbanos), el país fue sacudido por su primera crisis de sobreendeudamiento y de confrontaciones con 'sindicatos de deudores' entre 1999 y 2002. Esto empujó la naciente 'industria de las microfinanzas' a desarrollar mecanismos para un mejor manejo de la competencia, tal como oficinas de crédito y códigos de conducta para las instituciones. El episodio no perjudicó tanto incluso consolidó su importancia en el sector - a dos organizaciones no lucrativas: CRECER y PROMUJER, ambas orientadas hacia mujeres y con reputación de tener las prácticas más socialmente orientadas en el sector (Marconi \& Mosley, 2006).

El rendimiento promedio a nivel del continente es de 33.8\% (Martinez Ramírez, 2009, p.18). 
Evo Morales, líder del Movimiento al Socialismo (MAS), completó su primer mandato presidencial entre 2006 y 2009. Éste fue marcado por varias reformas importantes, incluyendo cambios a la constitución y la nacionalización de las industrias de hidrocarburos, pero también por una polarización de la política, manifiesta en el antagonismo entre el Poder Ejecutivo por un lado y los poderes Legislativo y Judicial por el otro, así como en las confrontaciones entre las poblaciones indígenas del Altiplano y las de zonas orientales del país. Con su victoria electoral aplastante en diciembre de 2009, el MAS ahora controla la mayor parte de las instituciones políticas, lo que ha eliminado los obstáculos de su período anterior. Sin embargo, las expectativas populares hacia sus mandatarios son aún más altas, por lo que ahora ya no pueden usar las trabas impuestas por la oposición como justificación de posibles incumplimientos. Además, las divisiones internas se hacen más visibles. El partido de Evo Morales está estructurado alrededor de dos componentes: uno está compuesto por militantes de movimientos izquierdistas históricos con experiencia en cargos públicos (en gobiernos nacionales o locales) y mantiene lazos cercanos con los dirigentes de las IMF. El otro, asociado a los grupos indígenas y movimientos populares, a menudo se encuentra en desacuerdo con el primero y tiene una postura mucho más ofensiva hacia el sector microfinanciero.

Esta izquierda algo dispar adopta una postura ambigua con respecto a las microfinanzas. Mientras que pinta a las IMF como 'usureros' durante las elecciones, con candidatos del MAS prometiendo préstamos con tasas de interés de un solo dígito, el partido sólo ha realizado tentativas tímidas y aisladas para convertir estas promesas en acciones reales. El marco regulatorio boliviano constituyó un modelo para las microfinanzas comerciales (Gómez, Tabares \& Vogel, 2000) porque priorizaba los beneficios y la estabilidad, animando la estandarización de prácticas en detrimento de los objetivos del desarrollo (Bédécarrats y Marconi, 2009, pp. 79-82). Surgió un cambio en 2006 cuando Evo Morales nombró, como Comisionado de la muy ortodoxa Comisión Bancaria, a un antiguo funcionario de banca pública que estuvo entre los primeros promotores de las microfinanzas en el país. Producto de esta reorientación, en 2008 las ONG que hasta entonces no eran reguladas, fueron colocadas bajo la supervisión del Banco Central. Pese a un proceso prolongado de acreditación, esta disposición abrió para las ONG la posibilidad de movilizar ahorros. Pero esta ventana de oportunidad para construir un sector microfinanciero no lucrativo, con orientación social y hacia las áreas rurales no parece ser una prioridad del gobierno. De hecho, poco después de estos cambios, la Comisión Bancaria fue remplazada por una autoridad de supervisión controlada por el Ministerio de Economía y Finanzas Públicas. La reforma afectó a todas las autoridades independientes del Poder Ejecutivo y fue acompañada por una gran rotación de personal. Al sustituir a especialistas financieros, considerados muy tecnócratas, con personas de menor experiencia, a menudo asignadas por afinidades partidarias, el cuerpo de supervisión perdió gran parte de su capacidad técnica de supervisar con eficacia un sector todavía vulnerable a la bancarrota o al fraude.

Además de la regulación, el gobierno ha impulsado políticas públicas de financiamiento. Con capital venezolano, creó el Banco de Desarrollo Productivo (BDP), controlado por el Estado para canalizar programas de transferencia de bonos sociales y refinanciar a instituciones microfinancieras, así como para proporcionar créditos 
directamente a organizaciones de artesanos y campesinos. Sin embargo, el capital inicial no fue renovado. El BDP es supervisado por cuatro ministerios que compiten por su control y sus actividades siguen siendo limitadas a un pequeño fondo de préstamo para instituciones financieras existentes. Durante la campaña electoral de finales de 2009, el discurso del MAS enfatizó la necesidad de crear un mecanismo de finanzas del desarrollo genuinamente controlado por el Estado, a menudo mencionado junto con una posible regulación de los tipos de interés de las IMF. Sin embargo, estas declaraciones tienen todavía que dar lugar a medidas concretas.

Aunque las posturas siguen siendo a menudo matizadas, los profesionales del sector microfinanciero denuncian frecuentemente las amenazas que perciben por parte del gobierno de tomar el mando de sus instituciones. Cabe mencionar que, entre las IMF, solamente AGROCAPITAL ha visto su desarrollo refrenado y esto por razones muy específicas. Esta institución, iniciada por USAID, participó activamente en los programas de erradicación de la coca y principalmente por esto fue puesta en la mira de las autoridades. Otras IMF no han sido afectadas, pero la situación podría evolucionar. En efecto, la nueva Constitución explícitamente da una voz a los movimientos sociales, haciendo una obligación el involucrarlos siempre que se utilicen los fondos públicos y, por extensión, fondos de los organismos de desarrollo internacionales. Esto ha reforzado el activismo de ciertos grupos cercanos al MAS en lo referente al sector de las microfinanzas.

A la luz de estas amenazas, algunas IMF están fomentando alianzas con bancos privados, previendo un decreto que obligue a estos últimos a dirigir parte de sus portafolios al microcrédito, como en Venezuela. Para muchas IMF, integrarse al sector bancario parece ser la mejor protección contra veleidades políticas. Los bancos no sólo están exentos de obligaciones de incluir a los movimientos sociales, ellos pueden aplicar tipos de interés particularmente altos en tarjetas de crédito sin la preocupación de sanciones. Otras IMF, en especial ONG afiliadas a la red nacional de microfinanzas, están apostando a profundizar el diálogo con las nuevas autoridades. Buscan demostrar su utilidad social construyendo alianzas con organizaciones de agricultores, mientras enfatizan su complementariedad a las políticas públicas ofreciendo mediar los programas de transferencia de efectivo del gobierno.

\subsection{Nicaragua: Crónica de una crisis anunciada}

El Banco de Desarrollo de Nicaragua entró en declive desde principios de los 90, durante la transición política entre el gobierno Sandinista y el Liberal, para cerrarse formalmente en 1998. Una primera ola de bancos comerciales creados al mismo tiempo cayó en bancarrota rápidamente, a menudo debido a fraudes. En este contexto, las IMF florecieron de varias formas. Los bancos comerciales de microfinanzas, supervisados por la comisión bancaria y autorizados para recolectar ahorros del público, experimentaron un crecimiento del 42 por ciento anual entre 2004 y 2008 (Superintendencia de Bancos, 2010; ASOMIF, 2010), apoyados por inversionistas públicos y privados. Mientras tanto, las ONG crecieron un promedio de 24 por ciento anual - algo más lento que sus contrapartes comerciales - debido a trabas regulatorias que les impiden movilizar ahorros, así como a las 
reticencias de los donantes públicos que, siguiendo las recomendaciones de instituciones multilaterales (Bastiaensen $\&$ Marchetti, 2007), decidieron no apoyar a organizaciones no lucrativas no reguladas, a menudo enfocadas en microfinanzas rurales. Sin embargo, el éxito de algunas ONG orientadas al mercado rural, tales como el Fondo de Desarrollo Local (FDL), Prestanic y Fundeser, generó un creciente interés entre los fondos de inversión social e incluso de fondos comerciales ${ }^{4}$. Existen también algunas cooperativas, pero éstas son significativamente más pequeñas. A finales de 2008 se estimó que los principales actores servían a más de medio millón de clientes, representando una porción significativa del - aproximadamente - un millón de pequeñas empresas en el país (Flaming, Duflos \& Helms, 2005). Aunque esta sea una estimación, la saturación del mercado es evidente, con la mayoría de los casos de sobreendeudamientos encontrándose en zonas urbanas y entre los ganaderos.

Procredit y Banex, dos bancos microfinancieros regulados, fueron designados como los 'campeones' de las microfinanzas rentables y se involucraron en una estrategia de expansión y competencia agresiva. Esto fue posible e incluso necesario debido a grandes inyecciones de liquidez por parte de donantes públicos y, en un menor grado, de inversionistas privados. Al hacer eso, intentaron eliminar IMF no reguladas que carecían de recursos financieros comparables. Sin embargo, gracias a su calidad institucional y su cobertura rural, muchas de estas IMF resistieron y lograron asegurar financiamiento internacional para sostener el crecimiento de su cartera.

Esta acometida apresurada llevó a un relajamiento del control de riesgo, préstamos múltiples y sobreendeudamiento, creando así las condiciones para una genuina crisis del sector accionada por una recesión aguda que golpeó fuertemente a los comerciantes en el 2009. Esta espiral llevó a muchas IMF a acumular malos préstamos y a un endurecimiento en sus prácticas de recolección. Particularmente afectado por la crisis, Banex fue liquidado en 2010, mientras que Procredit tuvo que ser recapitalizado por su contraparte internacional. El último, intentando moverse hacia una clientela más confiable, aumentó su cantidad mínima de préstamo a $\$ 2500$.

El partido Sandinista volvió al poder en Nicaragua en 2007, después de 18 años en la oposición. Su victoria no fue el resultado de más votos - registró el mismo 38 por ciento que había tenido por más de una década -, sino el fruto de una oposición dividida y de las maniobras políticas que permitieron que el candidato con más de 35 por ciento tomara la oficina sin una segunda vuelta electoral. Esto explica por qué la consolidación del apoyo popular se convirtió en la principal prioridad del nuevo gobierno. Éste buscó reforzar una relación clientelista por medio de programas sociales, incluyendo microcréditos subvencionados (financiados con fondos venezolanos) y redes económicas creadas alrededor de empresas privadas venezolano-nicaragüenses federadas bajo un consorcio llamado ALBA. Estas

\footnotetext{
Así, en 2008, las agencias multi y bilaterales representaron alrededor del 60\%. Representaron el 30\% de las fuentes de financiamiento para Procredit, el banco microfinanciero más grande del país y en gran medida orientado al sector urbano, mientras que correspondieron sólo al 13\% y 14\% para el fdl, el IMF no regulado más grande del país y principalmente rural. A la inversa, inversionistas sociales y comerciales representaban el 11\% del fondeo de Procredit, pero el 50\% para el fdl (Abarcar, citado por Roodman, 2010).
} 
relaciones fueron forjadas a través de intermediarios locales, como las cooperativas, que desempeñaron un papel importante como agentes subsidiaros dispensando subsidios a sus bases a cambio de su lealtad partidista (Rocha, 2010).

Es en este contexto que un movimiento impulsado por empresarios cercanos al partido Sandinista surgió en el norte del país en 2008. En un principio se propuso condenar las prácticas - tales como la incautación de garantías y la pena de prisión por mora - utilizadas por IMF supervisadas, únicas instituciones que permiten este tipo de recurso legal en caso de incumplimiento. Tras las negociaciones iniciales y el acuerdo entre los representantes locales del movimiento, conocido como No Pago y las IMF, el presidente Ortega instó a su audiencia a rebelarse en contra de esos «usureros» durante un discurso público en Jalapa el 13 de julio de 2008:

Yo les he dicho que hay que protestar, hay que reclamar; entiendo los reclamos, porque en un año y seis meses desmantelar todas las cadenas que nos impusieron los gobiernos al servicio de la oligarquía y el imperio no es fácil. Ellos nos fueron poniendo cadenas por todos lados. Han hecho bien en protestar en contra de los usureros, pero en vez de estar protestando en las carreteras protesten frente a las oficinas de los usureros y plántense frente a sus oficinas. Párense firmes, nosotros los apoyamos! (...) Amenazan con dejar de prestar, si el favor no lo están haciendo ellos, si lo que han hecho es un negocio para enriquecerse a costa de las necesidades de la gente después de que en 1990 desaparecieron los bancos que trabajaban con el pueblo (Vanegas, 2008).

Al siguiente día se desataron meses de violentos enfrentamientos entre los grupos de No Pago y el personal de las IMF, iniciando con el incendio de una ONG microfinanciera que no tenía nada que ver con los conflictos iniciales de reembolso, pero cuya cercanía con miembros de la oposición liberal era notoria.

Esta estrategia política se intensificó con la crisis de sobreendeudamiento de 2009. La situación fue explotada por las élites locales (a menudo entre los morosos con deudas más importantes) que eran los instigadores y coordinadores principales de los alborotos que al parecer maniobraban para reforzar sus redes clientelistas, asegurando a los grupos que sus deudas se cancelarían. El conflicto, algunas veces violento, continuó a lo largo de 2009 con el gobierno vacilando en sus posiciones hacia las microfinanzas, manteniendo en última instancia una política ambigua que reflejó las dinámicas locales de poder. Las demandas de la oposición cambiaron gradualmente de los problemas de pago hacia las tasas de interés. Bajo la presión del movimiento No Pago y con la ayuda de los políticos Sandinistas y no Sandinistas que representaban a los ganaderos del norte, un proyecto de ley fue introducido el 13 de abril de 2010 permitiendo que los morosos refinanciaran sus préstamos por cinco años a una tasa de 18 por ciento anual. A pesar del fervor que marcó la lucha por esta ley de moratoria, sólo una pequeña porción de los deudores del movimiento No Pago ha hecho uso de ella. Al parecer, la mayoría contó con condonaciones de deuda más significativas durante la campaña electoral de 2011. Sin embargo, la introducción de otro proyecto de ley para las microfinanzas, en junio de 2011, parece haber abierto una nueva era de relaciones más cooperativas entre el gobierno y el 
sector de las microfinanzas, y el apoyo político para el movimiento No Pago parece haber disminuido ${ }^{5}$. Cómo se desarrollarán estas relaciones está todavía por verse.

En este contexto, igual que en Bolivia, la tendencia consiste en que las $\mathrm{ONG}$ veteranas preparen su transformación hacia estructuras comerciales para ser reguladas por la Comisión Bancaria y así liberarse de la intervención gubernamental. Sin embargo, es una tendencia que limita el alcance de objetivos sociales, particularmente en el desarrollo rural. Aún frente a las amenazas políticas al sector privado, paradójicamente, reforzar su orientación mercantil ofrece una mejor protección regulatoria que el sector sin fines de lucro.

\subsection{Ecuador: cuestionamientos públicos que siguen siendo 'manejables' para el sector}

El sector de las microfinanzas en Ecuador se compone de organizaciones grandes, bancos y cooperativas supervisados por el Banco Central, una gama de ONG no reguladas, y pequeñas cooperativas. Además, hay dos bancos públicos que lamentablemente están mal administrados, operan a pérdidas, a veces son manipulados para fines electorales y dependen de inyecciones frecuentes de capital. Son considerados entre los más disfuncionales de la región (Trivelli \& Venero, 2007, pp. 88-102).

La izquierda ecuatoriana se unió alrededor de la coalición de Alianza País en 2006 para que Rafael Correa llegara al poder. Además de ser ex profesor de economía, tuvo una fugaz experiencia como Ministro de Finanzas antes de ser despedido bajo la presión de instituciones financieras internacionales, que se oponían a sus medidas. Poco después de tomar la oficina presidencial en enero de 2007, despidió al representante del Banco Mundial y puso en marcha un proceso de reformas constitucionales. En 2008 sentó las bases para importantes cambios en la política económica: mayor control de los recursos petrolíferos y énfasis en una economía basada en la solidaridad. Correa se rodeó de una élite poco representativa de los partidos gobernantes tradicionales: los ministros provenían de organizaciones no gubernamentales, empresas consultoras y, en menor grado, del mundo académico (Basabe-Serano, 2009).

A partir de su experiencia académica como profesor, el Presidente desarrolló un plan económico estructurado alrededor de tres áreas: público, privado-emprendedor y popular. Bajo este plan, la economía con base solidaria está en la unión de estas tres áreas e incluye la gestión participativa, los servicios sociales, la sociedad civil y las empresas de economía social. ${ }^{6}$ Diferente de la visión neoliberal "progresista" que buscaba incluir los empresarios individuales en el mercado principal, el enfoque de Correa, apoyado por la nueva Constitución, promueve su crecimiento en un ámbito económico que es un híbrido entre el capitalismo, el mutualismo y el Estado.

\footnotetext{
En el terreno, muchos deudores e IMF hoy en día tienden a negociar en forma bilateral y muy pragmática la reestructuración de la deuda a cambio de las propiedades (legalmente, pero no realmente) confiscadas, con el objetivo de dar vuelta a esta página tan pronto como sea posible.

6 El concepto de economía social se refiere aqui a las organizaciones que participan en actividades económicas definidas por un estatus de propiedad colectiva, tales como cooperativas, mutualidades, asociaciones o sindicatos.
} 
Una nueva ley, decretada el 11 de mayo de 2011, busca priorizar el concepto de «financiamiento popular». Éste se fundamenta en un criterio de propiedad colectiva y suplanta la noción de microfinanzas, definida por el tipo de productos ofrecidos y el nivel de pobreza de sus usuarios. Esta ley no reconoce un estatus propio para las ONG microfinancieras, incitándolas a convertirse en entidades con fines de lucro o en cooperativas. Hasta ahora, la ley continúa siendo vaga sobre las implicaciones prácticas de sus principios y varias modalidades cruciales tendrán que ser definidas en las regulaciones para finales del 2011. Por otra parte, el gobierno ha disputado la asignación de subvenciones internacionales para el desarrollo y ha creado un instituto para coordinar las iniciativas de los donantes. Por ahora, las nuevas prioridades no son restrictivas, pero los esfuerzos del gobierno para recoger la información y asignar cada $\mathrm{ONG}$ a un ministerio manifiestan su intención de incluir el sector no gubernamental en su esquema institucional.

El gobierno ha realizado cambios al marco regulatorio. Desde su toma de posesión, Correa ha amenazado en varias ocasiones a los "burócratas de oro" y criticó la independencia de algunas instituciones frente a los representantes elegidos por el pueblo. Por lo tanto, además de medidas transversales para reducir las escalas salariales de los funcionarios públicos, el Banco Central ha sido objeto de seguimiento más cercano. Los tecnócratas han sido sustituidos por personas elegidas bajo criterios partidarios y con menor capacidad técnica y experiencia. El presidente también se ha opuesto a las instituciones multilaterales, a menudo más simbólicamente que operativamente, por ejemplo en posturas mediatizadas contra el Banco Mundial y el FMI en 2007 y 2008, y a través del apoyo al Banco del Sur, relacionado con el ALBA y que todavía sólo existe en papel.

El gobierno también ha establecido un fondo de segundo piso, dotado con $\$ 40$ millones y administrado por el Ministerio de Desarrollo Social, para refinanciar a las IMF. Con el fin de asegurar la utilidad social de las instituciones apoyadas, las autoridades han desarrollado una metodología para evaluar su desempeño social que se basa en una herramienta de auditoría social ampliamente reconocida a nivel internacional (Zeller, Lapenu \& Greeley, 2003). También tiene un programa de crédito directo llamado el ' $5,5,5$ ', que presta $\$ 5000$ por 5 años a un 5 por ciento anual. Muchos observadores creen que el programa fue diseñado con propósitos electorales y denuncian su mala gestión. Algunos maliciosamente agregan el número '40' al nombre, refiriéndose a la tasa de mora del programa.

En este contexto, la Red Financiera Rural, plataforma que aglomera la mayor parte de las IMF del país, ha emergido como un cuerpo de mediación ineludible. Ha organizado sesiones de capacitación en microfinanzas para los nuevos empleados del Banco Central. Pero más importante, a la luz de los informes mordaces del gobierno y las declaraciones sobre los límites de tasas de interés, es que han llevado negociaciones intensas con el gobierno para asegurar que los techos sean aplicados de forma gradual. Como resultado, la mayoría de IMF ha logrado cumplir formalmente. Incluso la portavoz de un movimiento internacional muy importante de las microfinanzas comerciales ha admitido que "esta política por lo menos tiene la virtud de proporcionar señales claras y de permitir un tiempo de ajuste" (Rhyne, 2010). 


\section{Una relación compleja y ambivalente}

\subsection{Conflictos impregnados por un antagonismo ideológico}

En cada uno de los casos presentados arriba, el desacuerdo ocurrido entre las microfinancieras y los nuevos mandatarios públicos se deriva de un desafío al status quo sobre las prerrogativas del Estado y de la iniciativa privada. Las reformas neoliberales dieron la impresión de que el Estado se retiraba de sus funciones soberanas para dejar que el mercado organizara las actividades rentables y delegara la gestión de las poblaciones vulnerables a organizaciones autónomas sustentadas por la solidaridad privada o la ayuda internacional. Hoy, las microfinanzas y los movimientos socialistas tienen un campo en común, pero enfoques diferentes. Su misión prioritaria es la de mejorar las condiciones de vida de los pobres y excluidos, pero los primeros insisten en su especialización técnica y naturaleza apolítica, mientras que los últimos enfatizan la representación política y la justicia social.

A pesar de este propósito compartido y de su complementariedad potencial, los intentos de articular ambos sectores se enfrentan a diferencias profundas derivadas de su genealogía. Las microfinanzas han prosperado en el vacío dejado después de los ajustes estructurales, a menudo con el apoyo de las mismas instituciones internacionales contra las que los movimientos sociales de hoy están luchando (Rodríguez Carmona, 2008).

Los movimientos izquierdistas hacen reproches a las microfinancieras por una variedad de razones que juntas constituyen un argumento estructurado (Toro, 2009). En el centro está el debate sobre las tasas de interés, descritas como exorbitantes por los movimientos sociales que, por su ética, no admiten que la gente pobre pague proporcionalmente más que los ricos. Los proveedores de microfinanzas también son criticados por sus prácticas intransigentes de colección cuando se trata de recuperar préstamos de los clientes humildes, propensos a dificultades de pago. Tal firmeza contradice el discurso izquierdista, que destaca la responsabilidad colectiva sobre la individual cuando se trata de desigualdades (Bobbio, 1995). Una tercera queja contra las microfinanzas es que la oferta depende enteramente de la existencia de una demanda solvente. Los gobiernos izquierdistas desaprueban la renuencia de las microfinancieras para prestar durante crisis económicas y el efecto pro cíclico que induce tal aversión al riesgo. A nivel estructural, también critican las IMF por centrarse en zonas urbanas y en actividades de servicio y pequeño comercio, ignorando los sectores primarios o secundarios que figuran tan prominentemente en los planes de desarrollo de los movimientos socialistas.

Es útil analizar la historia de las relaciones de poder que fraguan las prácticas de deuda en América Latina. El 'peonaje', es decir la esclavitud por deuda, se encuentra en el corazón de los sistemas heredados de la época colonial (Chamoux, Dehouve \& Gouy-Gilbert, 1993). De hecho, la creación de instituciones públicas de fomento, las organizaciones autónomas de ahorro y crédito o las finanzas comerciales deben entenderse a través del vínculo político que sostienen sus relaciones de deuda. Este prisma explica por qué las cooperativas financieras, que proliferaron a mediados del Siglo XX, se dirigieron principalmente a aquellos con menor subordinación económica: estos eran los primeros capaces de organizarse para 
establecer mecanismos autónomos de intermediación financiera. También explica por qué tan tantos movimientos religiosos que tenían proyectos de sociedad - sean progresivos o conservadores, católicos o protestantes - crearon IMF para sustentar la transformación pretendida? También se puede analizar la creación de los bancos públicos como una forma del Estado para sustituir el tradicional caciquismo por nuevas lealtades partidistas (Lehmann, 1990). Según esta perspectiva, aunque los clientes de IMF no continúen sujetos a las obligaciones de reciprocidad que marcaron la historia colonial o el actual clientelismo político, a cambio deben someterse a precios elevados y una disciplina estricta de reembolso, que en ocasiones se traduce en una verdadera dependencia al crédito. Inversamente, cuando el gobierno critica las microfinanzas y distribuye préstamos subvencionados en nombre de la autonomía económica de los pobres - fenómeno particularmente común durante períodos electorales -; la atribución de estas ayudas es a menudo discrecional e implica para los beneficiarios una fidelidad electoral hacia el partido oficial, recreando sistemas de alienación política.

Aunque la oposición ideológica de las izquierdas a las microfinanzas se base en una acusación sustancial del sector, estos movimientos tienen todavía que proponer una alternativa viable. En los tres casos presentados arriba, los programas de crédito público de alto nivel han dado lugar a resultados decepcionantes. Estos fallos, como los de programas comparables en Venezuela (Penfold Becarra, 2007) privan a los socialistas de los ejemplos necesarios para enfrentar la ortodoxia a la cual se oponen. No obstante, los contra-ejemplos existen en Brasil, Chile y Guatemala ${ }^{8}$, en donde los proveedores públicos y privados están trabajando juntos para desarrollar los verdaderos métodos híbridos que aseguren sostenibilidad financiera. Paradójicamente, estos ejemplos no han atraído mucha atención en el nivel regional y todavía no se han reproducido en Bolivia, Ecuador o Nicaragua.

\subsection{Factores institucionales que afectan las microfinanzas}

Más allá de ideologías, las realidades locales son influenciadas por factores institucionales e intereses particulares que afectan la manera en que los conflictos surgen y son resueltos, sea por medio de compromisos o de confrontaciones. Los mensajes claros, pareados con medidas coherentes, son esenciales para permitir la colaboración entre agentes públicos y privados. Este no ha sido el caso en Bolivia o Nicaragua, en donde los gobiernos han tomado posiciones inconsistentes y, en ocasiones, contradictorias, con discursos opuestos entre ministerios distintos o incluso entre diferentes niveles de una misma administración.

\footnotetext{
En Nicaragua, por ejemplo, el FDL fue creado por la Compañía de Jesús y Prestanic por el Consejo de Iglesias Protestantes. Compartamos, la mayor IMF mexicana, fue fundada y es todavía en gran parte controlada por los tradicionalistas Legionarios de Cristo (en Bolivia y Ecuador las IMF basadas en la fe son menos importantes). Las microfinanzas incluso se han mencionado, aunque en términos muy vagos, en una encíclica papal: Benedicto XVI. Carta Encíclica en Veritae del Sumo Pontífice sobre el desarrollo humano integral en la caridad y la verdad, Roma, Vaticano, 29 de junio de 2009. Cabe señalar, sin embargo, que de acuerdo con sus diferencias ideológicas y programáticas, las organizaciones basadas en la fe no necesariamente comparten las mismas posiciones politicas con respecto al papel de las microfinanzas.

El Banco do Nordeste de Brasil, el INDAP en Chile y el BANRURAL en Guatemala. Para Brasil véase Abramovay et al. (2008) y para los otros dos véase Trivelli y Venero (2007).
} 
Los cuerpos de mediación son cruciales bajo estas circunstancias pues pueden ayudar a construir marcos de referencia comunes a instituciones políticas e IMF. Los comités técnicos de bancos centrales y los departamentos ministeriales desempeñaron un papel clave en Bolivia y Ecuador, traduciendo las intenciones políticas en medidas inteligibles y factibles. Sin embargo, la apropiación de estos órganos por parte del poder ejecutivo se ha traducido en una pérdida de la capacidad técnica, puesto que el personal menos experimentado es más influenciable por los políticos que encabezan sus ministerios de tutela, pero también por las instituciones que se supone deben supervisar. Es igualmente importante que los practicantes de las microfinanzas creen consenso alrededor de posiciones compartidas y se reúnan detrás de un portavoz común. En los tres países las redes nacionales de $\mathrm{IMF}^{9}$ han prosperado en un contexto marcado por tensiones políticas y han probado ser críticas para fomentar acuerdos que reconozcan el papel del sector a cambio de mayor transparencia en cuanto a su utilidad social. Han establecido sistemas de rendición de cuentas que han respondido a las preocupaciones locales y han visibilizado la contribución de las microfinanzas al bienestar público en un esfuerzo por mantener su autonomía.

Por otra parte, un análisis sociológico más detallado de las élites es útil para identificar las oportunidades de diálogo y para promover acercamientos. En muchos países, las ONG microfinancieras son lideradas por individuos inclinados hacia la izquierda que se incorporaron al sector asociativo cuando sus actividades de funcionario político o civil fueron amenazadas por la represión militar o ajustes estructurales. En Ecuador y Bolivia, varios encargados de IMF mantienen relaciones estrechas - e incluso amistades personales - con políticos prominentes de los partidos izquierdistas, lo que ha ayudado a generar acuerdos. En Nicaragua, la tensión entre las microfinanzas y el gobierno se debe mucho al hecho de que varios encargados de IMF son antiguos funcionarios del gobierno revolucionario de los años 80, ahora distanciados del nuevo gobierno de Daniel Ortega.

\subsection{Perspectivas estratégicas bajo limitaciones}

La tensión cada vez mayor entre las microfinanzas y los gobiernos socialistas afecta de forma distinta a las IMF dependiendo de sus características organizacionales y operativas. Como resultado han desarrollado estrategias diferenciadas que se representan en la tipología siguiente:

ASOMIF (www.asomif.org), fundada en 1992 en Nicaragua, RedFinanciera Rural (www.rfr.org.ec), fundada en 2000 en Ecuador, FINRURAL (www.finrural-bo.org) y Asofin (www.asofinbolivia .com), creados en 1993 y 1999 respectivamente, en Bolivia. 
Cuadro 2. Segmentación de las IMF: polarización del sector y desaparición de las microfinanzas transformativas

\begin{tabular}{|c|c|c|}
\hline $\begin{array}{c}\text { Características } \\
\text { institucionales y operativas }\end{array}$ & $\begin{array}{c}\text { Perspectiva de } \\
\text { gobiernos izquierdistas }\end{array}$ & Estrategia del sector \\
\hline $\begin{array}{l}\text { Microfinanzas } \\
\text { minimalistas: Enfoque } \\
\text { comercialmente agresivo, } \\
\text { inversión extranjera privada }\end{array}$ & $\begin{array}{l}\text { Segmento que es } \\
\text { más criticado pero } \\
\text { concretamente poco } \\
\text { amenazado por los } \\
\text { gobiernos }\end{array}$ & $\begin{array}{l}\text { Consolidar la } \\
\text { protección con derecho } \\
\text { mercantil. Adoptar } \\
\text { estándares mínimos de } \\
\text { responsabilidad social. } \\
\end{array}$ \\
\hline $\begin{array}{l}\text { Microfinanzas } \\
\text { transformativas: } \\
\text { Financieramente } \\
\text { sostenibles, sin fines de } \\
\text { lucro, ONG y cooperativas } \\
\text { financieras, políticamente } \\
\text { independientes y } \\
\text { comprometidas con el } \\
\text { cambio socioeconómico }\end{array}$ & $\begin{array}{l}\text { Segmento más expuesto } \\
\text { a la situación política: } \\
\text { regulación existente } \\
\text { muy desfavorable, } \\
\text { controversia sobre } \\
\text { sus relaciones con } \\
\text { organizaciones de } \\
\text { ayuda internacional } \\
\text { para el desarrollo, } \\
\text { criticadas por sus } \\
\text { tasas de interés, los } \\
\text { gobiernos niegan } \\
\text { su autonomía y su } \\
\text { capacidad de generar } \\
\text { alternativas sociales o } \\
\text { económicas }\end{array}$ & $\begin{array}{l}\text { Luchan por el } \\
\text { reconocimiento de } \\
\text { su contribución } \\
\text { al desarrollo pero } \\
\text { son fuertemente } \\
\text { incitadas a convertirse } \\
\text { en 'microfinanzas } \\
\text { minimalistas' o } \\
\text { en 'microfinanzas } \\
\text { solidarias'. }\end{array}$ \\
\hline $\begin{array}{l}\text { Microfinanzas solidarias: } \\
\text { Tasas de interés } \\
\text { subvencionadas, crédito } \\
\text { dirigido a sectores } \\
\text { económicos o sociales } \\
\text { específicos, viabilidad } \\
\text { financiera no es una } \\
\text { prioridad }\end{array}$ & $\begin{array}{l}\text { Segmento apoyado por } \\
\text { gobiernos socialistas, } \\
\text { riesgo de prácticas } \\
\text { clientelistas, y/o } \\
\text { instrumentalización } \\
\text { para los programas } \\
\text { económicos del } \\
\text { gobierno }\end{array}$ & $\begin{array}{l}\text { Buscan incidir } \\
\text { en las políticas } \\
\text { gubernamentales para } \\
\text { mayor reconocimiento y } \\
\text { convergencia estratégica. } \\
\text { Tentadas con renunciar } \\
\text { a su autonomía para } \\
\text { obtener fondos públicos. }\end{array}$ \\
\hline
\end{tabular}

Por años, el paradigma comercial priorizó la competencia como la mejor forma de mejorar la eficiencia del mercado microfinanciero. Hoy en día, los excesos y el crecimiento desenfrenado han dado lugar a crisis de sobreendeudamiento y en ocasiones a prácticas abusivas hacia los clientes. Ahora parecen ingenuos los esfuerzos previos de ciertos actores microfinancieros para evitar que el sector público regulara los aspectos sociales de su actividad o evaluara su contribución al desarrollo. Peor aún, incitaron el escepticismo de algunos gobiernos.

La visión minimalista de las microfinanzas, implicando en particular el abandono del acompañamiento mediante servicios no financieros - sean de salud, educación y desarrollo local - fue presentada por las instituciones multilaterales 
como un dechado de buena práctica. Ahora esta visión es fuertemente disputada. Irónicamente, el segmento de las microfinanzas que es puramente financiero, y el más lucrativo, está mayormente protegido contra las intromisiones políticas. No depende del sector público para su refinanciamiento y por otra parte está protegido por un marco jurídico sólido que los gobiernos tienen cuidado de no tocar.

Ciertamente las instituciones que arriesgan más son las que se han opuesto al paradigma comercial. Persiguiendo operaciones profesionales y sostenibles, han mantenido un fuerte compromiso hacia las metas de desarrollo y cambio social. Estas organizaciones, casi aniquiladas por la corriente dominante de las microfinanzas y las medidas regulatorias de los bancos centrales que favorecen a las empresas privadas y bancos, se encuentran ahora atrapadas en medio de un sector cada vez más polarizado, dominado por dos enfoques competidores: uno llevado por lógicas meramente mercantiles y el otro sometido a las políticas públicas. Si fallan en demostrar su importancia, no tendrán ninguna opción más que retirarse a la esfera comercial o someterse al control de autoridades políticas.

\section{Conclusión}

La relación particularmente tensa entre el gobierno y las IMF en Nicaragua, así como las situaciones más ambivalentes en Ecuador y Bolivia, son evidencia de la naturaleza polifacética y verdaderamente ambigua de los dos sectores. Por una parte, las izquierdas latinoamericanas tienen como objetivo declarado fomentar un desarrollo más equitativo, pero también son motivadas por el deseo de ensanchar su base social y tejer relaciones clientelistas que favorezcan su permanencia en el poder. Por otro lado, las IMF emergieron en vísperas de los fallos de bancos estatales y se presentaron como la única opción económicamente viable para financiar el desarrollo local. Sin embargo, en muchos casos se han desviado de su misión, ampliando sus operaciones de manera eminentemente comercial.

Citando los débiles resultados de las microfinanzas en términos de transformación económica, los gobiernos inclinados al socialismo están intentando intervenir directamente en la provisión de los servicios de crédito a los pobres. Pero debido a que estas intervenciones públicas son, ante todo, instrumentos políticos y carecen de los recursos humanos para una gestión sostenible a gran escala, tienden a ser esporádicas. Se complementan a menudo con programas mediados por IMF existentes que reciben financiamiento de la administración a cambio de aceptar condicionamientos sobre los sectores a los cuales tienen que ser dirigidos. A la luz de esto, tendría sentido negociar y fijar un marco regulatorio para prevenir los abusos, junto con políticas públicas complementarias que mejoren el alcance y el impacto de las microfinanzas. En lugar de eso, el oportunismo político lamentablemente tiende a llevar a la competencia efímera, pero intensa, entre las IMF existentes y los programas públicos temporales, así como a pequeñas y a menudo contradictorias reformas legales que en gran parte concuerdan con la ortodoxia financiera de la era anterior.

Paradójicamente, en los países estudiados esto ha exacerbado la polarización de los dos extremos del espectro microfinanciero. Por una parte, las instituciones 
más débiles tienden a atraer el apoyo gubernamental a cambio de entregar el control de sus operaciones, incluso si eso significa renunciar a la sostenibilidad financiera. Por otra parte, las instituciones más comerciales se protegen contra la amenaza de interferencia consolidando sus lazos con el sector privado. En resumen, parece que las instituciones bajo mayor amenaza son aquellas que, por medio de un enfoque que prioriza al desarrollo local, han logrado la viabilidad de forma autónoma.

Sin embargo, el debate sobre cómo redefinir los roles de los sectores público y privado en las finanzas de desarrollo implica entrelazar niveles locales e internacionales. Por tanto, es difícil saber cómo se desarrollará esta controversia. Un cambio en el posicionamiento de las grandes instituciones multilaterales, que hasta ahora defendieron la visión mercantil de las microfinanzas, o la aparición de un enfoque alternativo en países como Brasil, podría influir en las trayectorias nacionales que hemos analizado.

\section{Referencias bibliográficas}

Abramovay, R., Magalhães, R. \& Schröder, M. (2008). Social Movements Beyond the Iron Cage: Weak Ties in Territorial Development. World Development, 36(12), 2906-2920.

Adams, D. W., Graham, D. H. \& Von Pischke, J. D. (1984). Undermining Rural Development with Cheap Credit. Boulder: Westview Press.

Arditi, B. (2008). Arguments About the Left Turns in Latin America: A Post-Liberal Politics. Latin American Research Review, 43(3), 59-81.

Asociación Nicaragënse de Instituciones de Microfinanzas [ASOMIF]. (2010). Estadísticas. Recuperado el 12 de mayo de 2010, de www.asomif.org/index. php?option $=$ com_content $\&$ view $=$ article $\&$ id $=28 \&$ Itemid $=5$.

Basabe-Serano, S. (2009). Ecuador: reforma constitucional, nuevos actores políticos y viejas prácticas partidistas. Revista de Ciencia Política, 29(2), 381-406.

Bastiaensen, J. \& Marchetti, P. (2007). A Critical Review of CGAP-IADB Policies Inspired by the Fondo de Desarrollo Local, Nicaragua. Enterprise Development and Microfinance, 18 (2-3), 143-157.

Beasley-Murray, J., Cameron, M. A. \& Hersheberg, E. (2009). Latin America's Left Turns: An Introduction. Third World Quarterly, 30(2), 319-330.

Bédécarrats, F. \& Marconi, R. (2009). L'influence de la régulation sur la capacité de la microfinance à contribuer au développement: le cas de la Bolivie. Tiers Monde, 197, 71-90.

Bobbio N. (1995). Derecha e izquierda: razones y significados de una distinción politica, Madrid: Taurus.

Calderón, F. (2008). Una inflexión histórica. Cambio político y situación socioinstitucional en América Latina. Revista de la CEPAL, (96), 121-134.

Cameron, M. A. (2009). Latin America's Left Turns: Beyond Good and Bad”, en Third World Quarterly, 30(2), 331-348.

Castañeda, J. G. (2006). Latin America's Left Turn. Foreign Affairs, 85(3), 28-43.

Chamoux, M. N., Dehouve, D. \& Gouy-Gilbert, C. (1993). Prêter et emprunter. Pratiques de crédit au Mexique, XVIe-XXe siècle. Paris: MSH. 
Flaming, M., Duflos, E. \& Helms, B. Country-Level Effectiveness and Accountability Review. Washington, DC: CGAP.

Gómez, A., Tabares, G. \& Vogel, R. (2000). Regulation and Supervision of Microfinance Activities: The Bolivian Case Study. Washington: USAID-MBP.

Guérin, I., Lapenu, C. \& Doligez, F. (2009). La microfinance est-elle socialement responsable? Introduction. Tiers Monde, 197, 5-16.

Hall, P. \& Taylor, R. (1996). Political Science and the Three New Institutionalisms. Political Studies, 44(5), 936-957.

Helms, B. (2006). Access for All - Building Inclusive Financial Systems. Washington DC: CGAP.

Lehmann, D. (1990). Democracy and Development in Latin America: Economics, Politics and Religion in the Post-war Period. Philadelphia: Temple University Press.

Long, M. F. (Dir.). (1989). World Development Report. Financial Systems and Developement. New York: World Bank.

Marconi, R. \& Mosley, P. (2006). Bolivia during the global crisis 1998-2004: towards a macroeconomics of microfinance. Journal of International Development, (18), 237-261.

Martínez Ramírez, R. (2009). Latin America and Caribbean Microfinance Analysis and Benchmarking Report. Washington, DC: The Mix. Recuperado el 15 de enero de 2010, de http://www.themix.org/publications/mix-microfinanceworld/2011/01/microfinance-market-report-latin-america-and-caribbean-2.

Morduch, J. (1999). The Microfinance Promise. Journal of economic literature, 37(4), 1569-1614.

Moreno-Brid, J. C. \& Paunovic, I. (2008). What is New and What is Left of the Economic Policies of the New Left Governments in Latin America. International Journal of Political Economy, 37(3), 82-108.

Mosley, P. (2009). La 'trampa política de la pobreza': Bolivia 1999-2009. Cuadernos Económicos de ICE, (78), 57-98.

Padilla, P. (2008). Las microfinancieras somos políticamente muy atractivas. Envio, (317). Recuperado el 30 de mayo de 2010, de www.envio.org.ni.

Penfold-Becerra, M. (2007). Clientelism and Social Funds: Evidence from Chávez's Misiones. Latin American Politics and Society, 49(4), 63-84.

Rhyne, E. (2010). Microfinance among the Populists. The Huffington Post, (11), 06.

Rocha Gómez, J. L. (2010). Crisis institucional en Nicaragua: entre un Estado privatizado y un Estado monarquizado. Nueva Sociedad, (228), 4-13.

Rodríguez Carmona, A. (2008). El Proyectorado: Bolivia tras 20 años de ayuda externa. La Paz: Oxfam.

Roodman, D. (2010). Who Inflated the Microcredit Bubbles?. David Roodman's Microfinance Open Book Blog. Center for Global Development. Recuperado el 25 de abril de 2010, de http://blogs.cgdev.org/open_book/2010/03/whoinflated-the-bubbles.php.

Rosenberg, R., González, A. \& Narain, S. (2009). The New Moneylenders: Are the Poor Being Exploited by High Microcredit Interest Rates? Washington DC: CGAP.

Superintendencia de Bancos. (2010). Compilado de datos. Recuperado el 12 de mayo de 2010, de www.superintendencia.Gob.ni/index.php?Temp cont $=\& i d=10 \&$ Seccion $=1$. 
Toro, G. (2009). La pobreza: un gran negocio-análisis crítico sobre Oeneges, Microfinancieras y Banca. La Paz: Mujeres creando.

Trivelli, C. \& Venero, H. (2007). Banca de desarrollo para el agro: experiencias en curso en América Latina. Lima: IEP.

Vanegas, L. (2008, 13 de julio). En Jalapa Ortega azuza plantones: sugiere protestas "frente a oficinas de esos usureros". El Nuevo Diario. Recuperado el 2 de mayo de 2010, de http://www.elnuevodiario.com.ni/nacionales/21296.

Weber, H. (2002). The Imposition of a Global Development Architecture: The Example of Microcredit. Review of International Studies, 28(3), 537-555.

Zeller, M., Lapenu, C. \& Greeley, M. (2003). Measuring social performance of microfinance institutions: A proposal. Washington DC: Argidius-CGAP. 